\title{
Assessing Environmental Impact on Mass Balance, Carrying Capacity and Growth of Exploited Populations
}

\author{
A. L. Jensen \\ School of Natural Resources, University of Michigan, Ann Arbor, Michigan 48103, USA
}

\begin{abstract}
Population models that have been applied for assessment of exploited populations are also useful for assessment of environmental impacts. Surplus production models have been applied for both fishery and environmental impact assessment; environmental impacts with three different modes of action can be incorporated into the surplus production model. For each of these possible modes of action the equilibrium relations among biomass, yield, level of fishing and level of environmental stress are developed. The resulting equations are applied to describe the results of laboratory experiments in which exploited populations were manipulated to alter the growth coefficient, carrying capacity, or mass balance. The models describe the experimental results.
\end{abstract}

\section{INTRODUCTION}

Surplus production models have been widely applied for assessing the impact of fishing on fish populations and to determine optimum levels of exploitation (e.g. Schaefer, 1954, 1957; Pella \& Tomlinson, 1969: Fox, 1970; Ricker, 1975; Jensen, 1976, 1978). More recently, surplus production models have been applied for assessment of environmental impacts (Jensen, 1982; Jensen et al., 1982). In development and application of surplus production models for fisheries assessment it is assumed that the impact of fishing is on mass balance; the biomass accumulation by fishermen equals the loss of biomass from the exploited population. Some environmental impacts such as impingement of fishes at power plants

Environ. Pollut. Ser. A. 0143-1471/84/\$03.00 Elsevier Applied Science Publishers Ltd. England, 1984. Printed in Great Britain 
remove biomass and can be modelled like a fishery. The mode of impact of stresses such as a low $\mathrm{pH}$ which might kill mainly young fish and decrease reproduction is uncertain.

There are three ways that an impact can be introduced into the logistic equation. An impact can affect the mass balance, it can change the coefficient of increase. or it can change the environmental carrying capacity. The properties of logistic surplus production models in which these different impacts are introduced are examined and the results are compared. Laboratory data are applied to test the predictions of the models.

\section{LOGISTIC SURPLUS PRODUCTION MODEL}

Surplus production models assume that every population has some capacity to increase which is a function of population size and which is a maximum at some intermediate population size. If it is assumed that fishing removes biomass at the rate $\mathrm{d} Y / \mathrm{d} t=q E B$ and that the biomass dynamics of a population are described by the logistic equation, then the yield model is:

$$
\begin{aligned}
& \mathrm{d} Y / \mathrm{d} t=q E B \\
& \mathrm{~d} B / \mathrm{d} t=k B-k B^{2} / B_{x}-q E B
\end{aligned}
$$

where $B=$ population biomass $(\mathrm{kg})$

$Y=$ cumulative yield from the fishery $(\mathrm{kg})$

$k=$ population growth coefficient (per year)

$B_{x}=$ carrying capacity in terms of biomass $(\mathrm{kg})$

$q=$ catchability coefficient $(\mathrm{kg}$ per unit of effort)

$E=$ fishing effort (number of gear units multiplied by time of operation)

The logistic surplus production model and methods for application of the model were developed by Volterra (1928), Hjort et al. (1933), Graham (1935) and Schaefer (1954, 1957).

Aspects of the logistic surplus production model important for fishery management are well known. Under equilibrium conditions where $\mathrm{d} B / \mathrm{d} t=0$, the relation between biomass and yield is the parabola:

$$
Y_{\mathrm{e}}=k B-k B^{2} / B_{x}
$$


where $Y_{\mathrm{e}}$ is the annual equilibrium yield. The maximum sustainable yield (MSY) of $k B_{x} / 4$ occurs at a biomass of $B_{x} / 2$. For every level of fishing such that $q E<k$ population size will approach the equilibrium value:

$$
B_{\mathrm{e}}=B_{\gamma}-\left(q B_{x} / k\right) E
$$

This equation indicates that there is a linear decrease in biomass with increase in fishing effort. Logistic population growth assumes that as fishing effort increases the mortality rate increases; this reduces the size of the population but as the population size decreases the birth rate increases and, if the fishing effort is such that $q E<k$, the population size will approach an equilibrium where the birth rate balances the death rate.

\section{MODIFICATION FOR ENVIRONMENTAL IMPACT ASSESSMENT}

An environmental stress can act on a population in three different ways. The stress can act on mass balance, it can affect the capacity of a population to increase, or it can operate on the carrying capacity $B_{x}$.

\section{Impact on mass balance}

Some environmental impacts, such as impingement at a power station, kill members of the population just as a fishery, and these impacts can be modelled with equations identical to those applied for fishery assessment (Jensen, 1982: Jensen et al., 1982). If the impact removes individuals at the rate $\mathrm{d} l: \mathrm{d} t$, and the fishery continues to operate, the surplus production model becomes:

$$
\begin{aligned}
\mathrm{d} I / \mathrm{d} t & =g Q B \\
\mathrm{~d} Y: \mathrm{d} t & =q E B \\
\mathrm{~d} B / \mathrm{d} t & =k B-k B^{2} / B,-q E B-g Q B
\end{aligned}
$$

where $l$ is the accumulated number killed to time $t, g$ is a coefficient that measures the impact per unit of impact intensity, and $Q$ is the measure of impact intensity.

Equations (5), (6) and (7) can be used to develop several useful relations among the population parameters and the level of impact. For every value 
of $E$ and $Q$ such that $(q E+g Q)<k$, population biomass will approach an equilibrium given by:

$$
B_{\mathrm{c}}=B_{x}(1-q E / k-g Q / k)
$$

which indicates that population size decreases linearly with increase in fishing effort and with increase in the level of environmental stress. The two sources of stress are additive; there is no interaction.

Under equilibrium conditions where $\mathrm{d} B / \mathrm{d} t=0$, annual equilibrium yield is given by:

$$
Y=k B-k B^{2} / B_{x}-g Q B
$$

An environmental impact changes the location of the stock production curve and moves the entire curve closer to the origin (e.g. Fig. 1). The maximum sustainable yield (MSY) occurs at a biomass of:

$$
B_{\mathrm{MSY}}=B_{\mathrm{x}}(1-g Q / k) / 2
$$

which is a smaller biomass than the biomass at the MSY of $B_{x} / 2$ for a population receiving no environmental impact. Substitution of eqn (10) into the equilibrium yield equation (eqn (9)) gives the relation between the

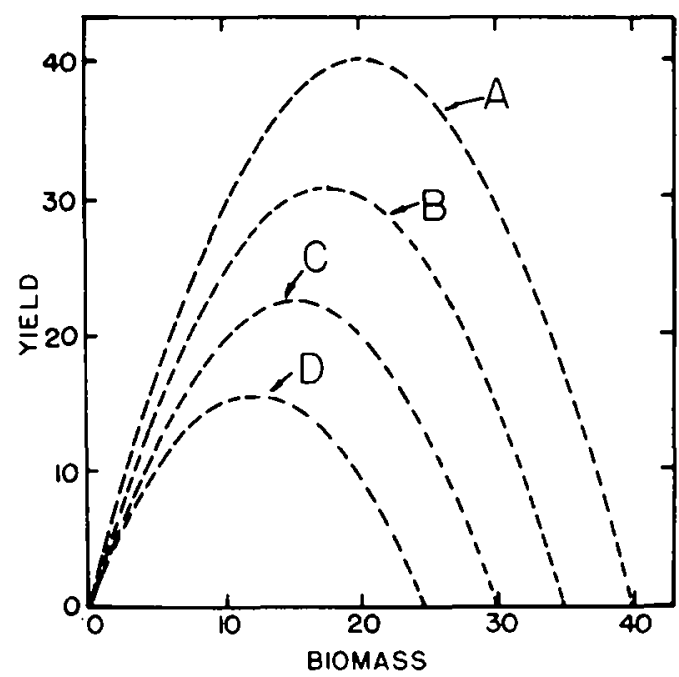

Fig. 1. Equilibrium yield curves for exploited populations stressed by an environmental factor that acts on mass balance: the level of impact decreases from curve $A$ to curve $D$. Parameters are $k=0.40, q=2 \times 10^{-5}, B,=4 \times 10^{7}$. 
MSY and the level of environmental stress as (Jensen, 1982: Jensen et al.. 1982):

$$
\mathrm{MSY}=k B_{x} / 4-g B_{x} Q / 2+g^{2} B_{x} Q^{2} / 4 k
$$

The impact of an environmental stress on the MSY is not linear.

\section{Impact on the population growth coefficient}

An environmental impact that decreases fecundity or changes the age structure can impact on the capacity of a population to increase. One of the impacts of a fishery is a change in age structure with a reduction in the number of older individuals; this change could decrease $k$ but this is ignored in assessment of fishing. A surplus production model for an exploited population in which the rate of increase is affected by an environmental impact is:

$$
\begin{aligned}
& \mathrm{d} Y / \mathrm{d} t=q E B \\
& \mathrm{~d} B / \mathrm{d} t=(k-g Q) B-(k-g Q) B^{2} / B_{\propto}-q E B
\end{aligned}
$$

At every level of fishing and environmental stress such that $q E+g Q<k$. population biomass will approach the equilibrium value:

$$
B_{\mathrm{e}}=B_{x}-q E B_{x_{x}} /(k-g Q)
$$

The impact of fishing and the impact of an environmental stress are not additive for impacts that act on the coefficient of increase. If the population is not exploited, the second term on the right is zero and there is no impact of the environmental stress on population size. The fishery causes biomass to decrease because it operates on mass balance; an environmental stress intensifies the impact of a fishery on biomass because it reduces the capacity of a population to increase in response to an impact on mass balance.

The relation between annual equilibrium yield and biomass is:

$$
Y_{\mathrm{c}}=(k-g Q) B-(k-g Q) B^{2} / B_{\gamma}
$$

Equation (15) is a parabola (Fig. 2) but the dome is not as sharp as that for the logistic model. The environmental stress pushes down the dome of the stock production curve but does not move the entire curve toward the origin as was the case with an impact that acted on mass balance. The biomass at the MSY is $B_{x} / 2$, just as for the logistic model without 


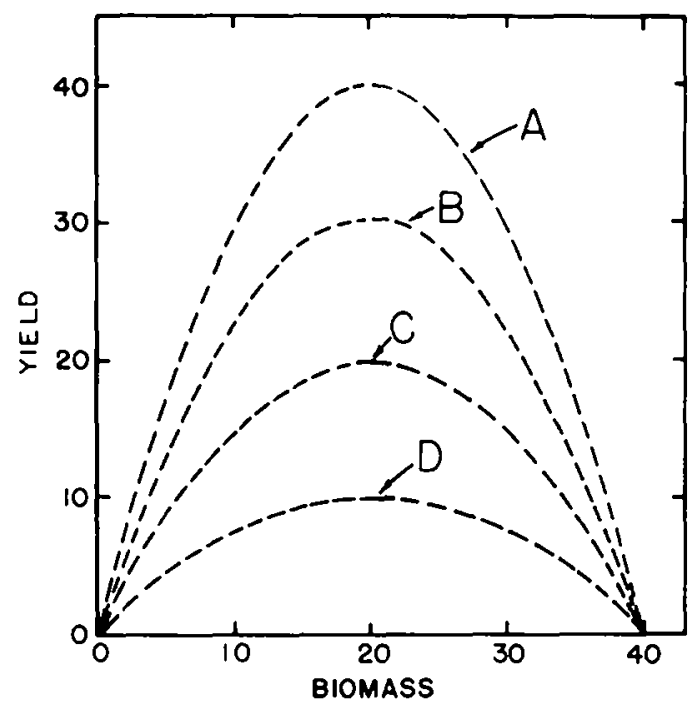

Fig. 2. Equilibrium yield curves for exploited populations stressed by an environmental factor that acts on the coefficient for increase $k$; the level of impact decreases from curve $A$ to curve D. Parameters are $k=0 \cdot 40, q=2 \times 10^{-5}, B,=4 \times 10^{\text {? }}$.

environmental impacts, but the MSY is decreased by the environmental stress to:

$$
\mathrm{MSY}=(k-g Q) B_{x} / 4
$$

\section{Impact on carrying capacity}

An environmental stress can act on the carrying capacity, for example by decreasing the food supply or by decreasing the area that can be inhabited. If the impact is on the carrying capacity, the surplus production model becomes

$$
\begin{aligned}
& \mathrm{d} Y / \mathrm{d} t=q E B \\
& \mathrm{~d} B / \mathrm{d} t=k B-k B^{2} /\left(B_{x}-g Q\right)-q E B
\end{aligned}
$$

For all values of $Q$ and $E$ sufficiently small, the population biomass approaches the equilibrium:

$$
B_{\mathrm{c}}=B_{x}(1-q E / k)(1-g Q)
$$




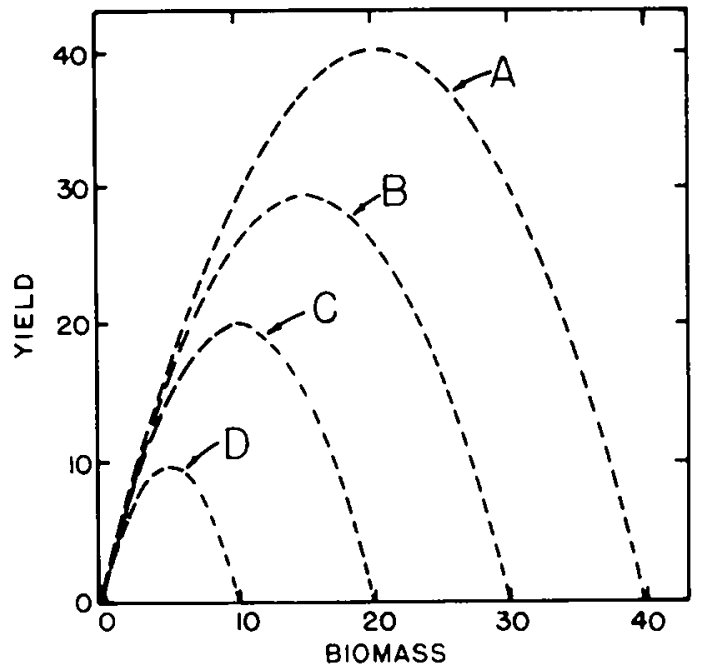

Fig. 3. Equilibrium yield curves for exploited populations stressed by an environmental factor that acts on the carrying capacity: the level of impact decreases from curve $A$ to curve D. Parameters are $k=0.40, q=2 \times 10^{-5} . B,=4 \times 10^{7}$.

The impacts of fishing and an environmental stress are not additive when the impact is on the carrying capacity. If the impact of an environmental stress is on the carrying capacity, the impact on biomass has additive components for exploitation and impact, and there is an interactive component.

At equilibrium where $\mathrm{d} B / \mathrm{d} t=0$, annual yield is given by the equation:

$$
Y_{\mathrm{c}}=k B-k B^{2}{ }_{i} B_{x}(1-g Q)
$$

An environmental impact operating on the carrying capacity changes the location of the stock production curve like an impact on mass balance (Fig. 3). The MSY occurs at a biomass of:

$$
B_{\mathrm{MSY}}=B_{x}(1-g Q) ;
$$

and the MSY is:

$$
\mathrm{MSY}=k B_{r}(1-g Q) ; 4
$$

Both the biomass at the MSY and the MSY are decreased by an environmental impact that operates on the carrying capacity. 


\section{RESULTS AND DISCUSSION}

The three different modes of impact that can be modelled with the logistic surplus production model result in considerably different relations between the level of impact and equilibrium biomass, equilibrium yield and the MSY. Experimental data are available to verify most of the relations predicted by the models. However, I know of no laboratory data for the combined impacts of fishing and an environmental stress that is known to operate only on mass balance. Jensen \& Marshall (1982) modelled the impact of radiation stress as though the only impact were on mass balance and, although the mode of impact was not known for certain, the results indicate that the main impact may have been on mass balance. The analysis of Jensen \& Marshall (1982) was based on a population study of Daphnia pulex in the laboratory; the study was a $4 \times 4$ factorial experiment with instantaneous fishing mortality rates of $0 \cdot 16,0.51,1.05$ and 2.30 per week and four levels of radiation stress administered by placing cultures at different distances from a $30 \mathrm{Ci}^{60} \mathrm{Co}$ source. Numbers of Daphnia rather than biomass were determined.

The estimates of the parameters of the surplus production model modified for an impact on mass balance were $B_{x}=192$ individuals, $k=3.7$ per week and $g=0.003$ per week (Jensen \& Marshall, 1982). For an environmental stress that acts on mass balance, biomass as a function of fishing effort and the level of environmental stress is given by eqn (8); substitution of the parameter estimates gives:

$$
N_{\mathrm{e}}=192-51.89 \mathrm{~F}-0.16 Q
$$

where $N_{\mathrm{e}}$ is the equilibrium population size in terms of numbers and $F$ is the instantaneous fishing mortality coefficient.

Note that $q E=F$ and $Y_{\mathrm{e}}=N_{\mathrm{e}} F$, from which:

$$
Y_{\mathrm{e}}=192 F 51 \cdot 89 F^{2}-0 \cdot 16 Q F
$$

The fitted equations were applied to estimate the observed yield and biomass. The coefficients of determination were 0.94 for numbers and 0.92 for yield. The model does not appear to perform well for very high rates of fishing or environmental stress, but generally the estimated biomass and yield values are close to the observed values (Tables $I$ and 2): overall, the indication is that the main impact of radiation stress is on mass balance.

Laboratory data for an impact on $k$ for an exploited population do not 
TABLE 1

Observed Number, and Predicted Number in Parentheses, of Daphnia puler with Different Exploitation Rates (Percentage Removal per Three-Week Brood Interval) and Different Levels of Radiation Stress

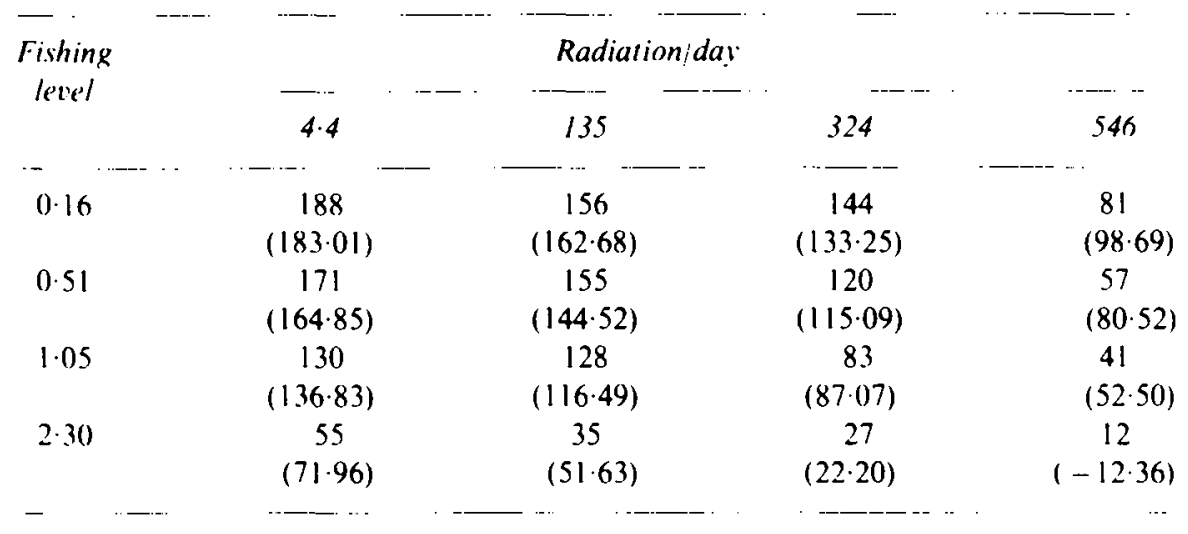

appear to be available, but the impact on $k$ for an unexploited population was studied by Slobodkin \& Richman (1956). They studied growth of Daphnia pulicaria populations under two temperatures and two food levels with seven different levels of removal of newborn (Table 3). Removal of newborn is an impact on fecundity and decreases the rate of increase. The model indicates that if the environmental impact is on $k$ there will be no impact on the biomass of adults of an unexploited

\section{TABLE 2}

Observed Yield, and Predicted Yield in Parentheses, of Daphnia pulex with Different Exploitation Rates (Percent Removal per Three-Week Brood Interval) and Different Levels of Radiation Stress

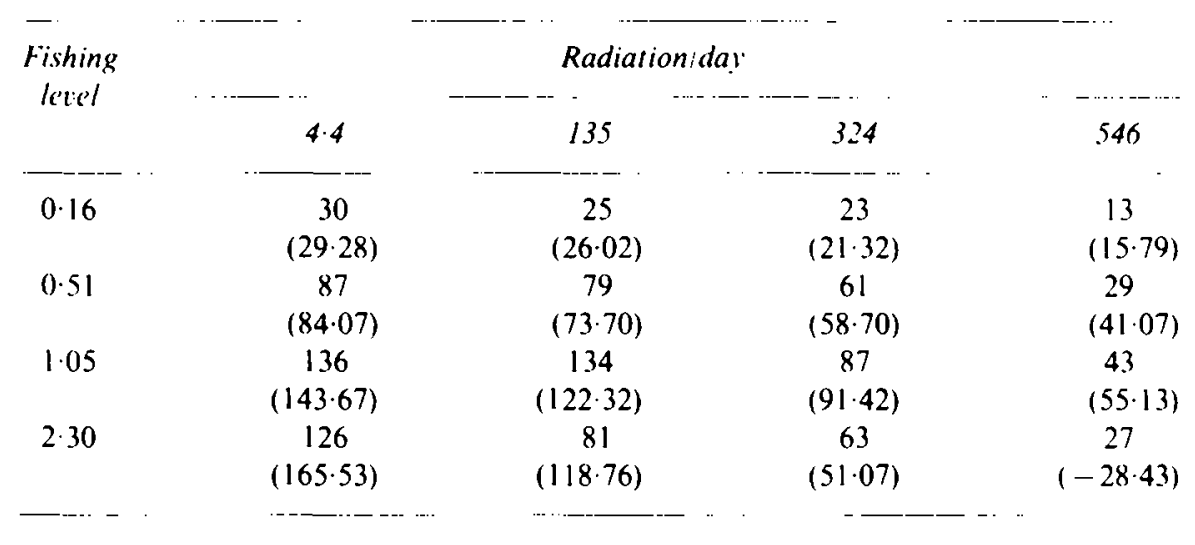


TABLE 3

Observed Number of Adult Daphnia pulicaria at Different Levels of Removal of Newborn and with Different Levels of Food and Temperature ${ }^{a}$

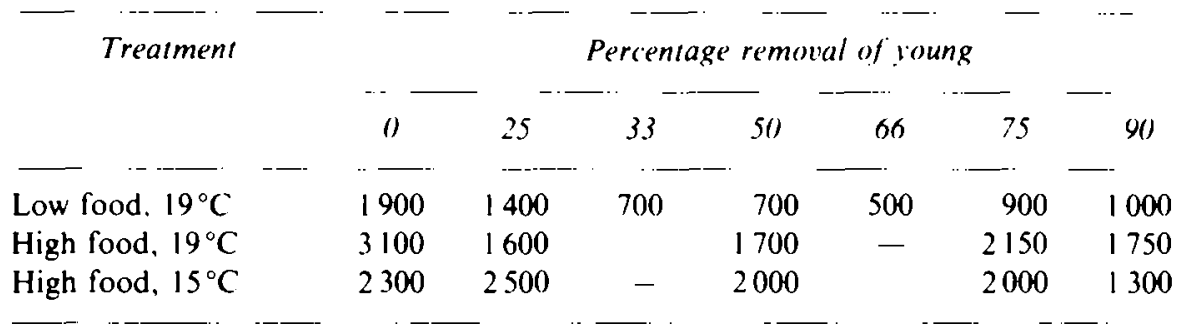

${ }^{-}$The numbers were read from Tables 5.6 and 7 of Slobodkin \& Richman (1956).

population and this relation is much different from that of an environmental impact on mass balance. There is considerable variation in average densities of the Daphnia populations but there is little change in the size of the adult populations even when the removal rate of young is $90 \%$ (Table 3). A $90 \%$ removal of adults would have a large impact on population biomass (Silliman \& Gutsell, 1958; Silliman, 1968). The impact of a stress on adult biomass depends on the mode of action.

Growth of exploited populations of guppies Lebistes reticulatus with different levels of food was studied by Silliman (1968). Nine guppy populations were grown on three diets with ratios to a standard diet of $0.50,1.0$ and 1.5 and exploited at rates of 25,33 and $50 \%$ per three-week brood interval. The carrying capacities of these populations were controlled by the diet level and $B_{x}$ increased with increase in the amount of food (Silliman, 1968). To fit the surplus production model modified for an impact on the carrying capacity to Silliman's (1968) data, the rates of exploitation were converted to instantaneous fishing mortality coefficients which gave $0,0.29,0.42$ and 0.69 per three weeks. The levels of environmental impact were calculated from the food ratios as $Q=(1.5-$ food ratio) to give values of $Q$ of $0,0.5$ and 1 . The carrying capacity was estimated as the average biomass of the unfinished high food level tank and was $41.2 \mathrm{~g}$. The relation between the observed average population size and $Q$ for the unexploited populations gave a value of $g$ of 0.64 per three weeks. A $k$ value of 0.78 per three weeks was calculated with non-linear least squares. Substitution of the parameter estimates into eqn (19) gives:

$$
B_{\mathrm{c}}=41 \cdot 2-26 \cdot 78 Q-52 \cdot 82 F+34 \cdot 33 F Q
$$




\section{TABLE 4}

Observed and Predicted Biomass, in Parentheses, of Guppies with Different Levels of Exploitation (Instantaneous Rates per Three-Week Brood Interval) and Different Levels of Food Relative to a Standard Diet

\begin{tabular}{|c|c|c|c|}
\hline \multirow{2}{*}{$\begin{array}{c}\text { Fishing } \\
\text { level }\end{array}$} & & Food level & \\
\hline & 0.5 & 1.0 & 1.5 \\
\hline 0 & $\begin{array}{c}14.9 \\
(14.42)\end{array}$ & $\begin{array}{c}26.4 \\
(27 \cdot 81)\end{array}$ & $\begin{array}{c}41 \cdot 2 \\
(41 \cdot 20)\end{array}$ \\
\hline $0 \cdot 25$ & $\begin{array}{c}9 \cdot 3 \\
(9 \cdot 80)\end{array}$ & $\begin{array}{c}13 \cdot 3 \\
(18 \cdot 90)\end{array}$ & $\begin{array}{c}17.5 \\
(28.00)\end{array}$ \\
\hline 0.33 & $\begin{array}{c}7 \cdot 0 \\
(8 \cdot 32)\end{array}$ & $\begin{array}{c}10 \cdot 5 \\
(16.04)\end{array}$ & $\begin{array}{c}16 \cdot 3 \\
(23 \cdot 77)\end{array}$ \\
\hline 0.50 & $\begin{array}{c}3.9 \\
(5 \cdot 16)\end{array}$ & $\begin{array}{c}6.2 \\
(9.98)\end{array}$ & $\begin{array}{c}8.7 \\
(14.79)\end{array}$ \\
\hline
\end{tabular}

For determination of the impact on yield the relation between yield and effort is better than that between yield and biomass (eqn (20)). Substitution of $B=Y / q E$ into the yield equation (eqn (20)) and solution for $Y$ gives:

$$
Y_{\mathrm{c}}=F B_{x}-g Q F-B_{x} F^{2} / k+g Q F^{2} / k
$$

The fitted equation is:

$$
Y_{\mathrm{e}}=41 \cdot 2 F-26 \cdot 78 F Q-52 \cdot 82 F^{2}+34 \cdot 33 Q F^{2}
$$

The coefficients of determination for biomass and yield were 0.95 and 0.91 ; the equations predicted the observed biomass and yield except at high values of fishing effort and environmental stress (Tables 4 and 5).

Population responses to impacts on mass balance, the coefficient for increase $k$ and the environmental carrying capacity are considerably different. The experimental data indicate that modification of the logistic surplus production model for environmental impacts describes the dynamics of laboratory populations under exploitation and environmental stress. The surplus production model is a simple model to apply for assessment of fish populations when catch and effort data are available. Modifications of the model that include one or more types of environmental stress easily can be applied if the impact of the stress can be 
TABLE 5

Observed and Predicted Yields, in Parentheses, of Guppies with Different Levels of Exploitation (Instantaneous Rates per Three-Week Brood Interval) and Different Levels of Food Relative to a Standard Diet

\begin{tabular}{|c|c|c|c|}
\hline \multirow{2}{*}{$\begin{array}{c}\text { Fishing } \\
\text { level }\end{array}$} & & Food level & \\
\hline & 0.5 & 1.0 & 1.5 \\
\hline 0.25 & $\begin{array}{c}2 \cdot 3 \\
(2 \cdot 45)\end{array}$ & $\begin{array}{c}3.7 \\
(4 \cdot 72)\end{array}$ & $\begin{array}{c}5.4 \\
(7.00)\end{array}$ \\
\hline 0.33 & $\begin{array}{c}2.2 \\
(2.75)\end{array}$ & $\begin{array}{c}3.9 \\
(5 \cdot 29)\end{array}$ & $\begin{array}{c}5.9 \\
(7.84)\end{array}$ \\
\hline 0.50 & $\begin{array}{c}2 \cdot 2 \\
(2 \cdot 59)\end{array}$ & $\begin{array}{c}3.0 \\
(4.99)\end{array}$ & $\begin{array}{c}4.8 \\
(7 \cdot 40)\end{array}$ \\
\hline
\end{tabular}

measured as in power plant impingement. The model also may be useful in the laboratory for identification of the mode of action of environmental stress.

\section{REFERENCES}

Fox, W. W. (1970). An exponential yield model for optimizing exploited fish populations. Trans. Am. Fish. Soc., 99, 80-8.

Graham, M. (1935). Modern theory of exploiting a fishery and application to North Sea trawling. J. Cons. int. Explor. Mer, 10, 264-74.

Hjort, J., John, G. \& Ottestad, P. (1933). The optimum catch. Hvalradets Skr. 7, 92-127.

Jensen, A. L. (1972). Population biomass, number of individuals, average individual weight, and the linear surplus production model. J. Fish. Res. Bd Can., 29, 16515.

Jensen, A. L. (1976). Assessment of the United States lake whitefish fisheries of Lake Superior, Lake Michigan, and Lake Huron. J. Fish. Res. Bd Can., 33, $747-59$.

Jensen, A. L. (1978). Assessment of the lake trout fishery in Lake Superior: 1929-1950. Trans. Am. Fish. Soc., 107, 5439.

Jensen, A. L. (1982). Impact of a once through cooling system on the yellow perch stock in the western basin of Lake Erie. Int. J. ecol. Modelling. 15. $127-44$

Jensen, A. L. \& Marshall, J. S. (1982). Application of a surplus production model to assess environmental impacts on exploited populations of Daphnia pulex in the laboratory. Environ. Pollut. Ser. A, 28, 273-80. 
Jensen, A. L., Spigarelli, S. A. \& Thommes, M. M. (1982). Use of conventional fishery models for assessment of entrainment and impingement impacts on three Lake Michigan fish species. Trans. Am. Fish. Soc., 111, 2134.

Pella, J. J. \& Tomlinson, P. K. (1969). A generalized stock production model. Bull. Inter-Am. Trop. Tuna Commn, 13, 419-96.

Ricker, W. E. (1975). Computation and interpretation of biological statistics of fish populations. Bull. Fish. Res. Bd Can., 191.

Schaefer, M. B. (1954). Some aspects of the dynamics of populations important to the management of the commercial marine fisheries. Bull. Inter-Am. Trop. Tuna Commn, 1, 27-56.

Schaefer, M. B. (1957). A study of the dynamics of the fishery for yellowfin tuna in the eastern tropical Pacific Ocean. Bull. Inter-Am. Trop. Tuna Commn, 2, 247-68.

Silliman, R. P. (1968). Interaction of food level and exploitation in experimental fish populations. Fishery Bull. Fish Wildl. Sert. U.S., 66, 425.39.

Silliman, R. P. \& Gutsell, J. S. (1958). Experimental exploitation of fish populations. Fishery Bull. Fish Wildl. Serv. U.S., 133, 215-52.

Slobodkin. L. B. \& Richman, S. (1956). The effect of removal of fixed percentages of the newborn on size and variability in populations of Daphnia pulicaria (Forbes). Limnol. Oceanogr., 1, 20937.

Volterra, V. (1928). Variations and fluctuations of the number of individuals in animal species living together. J. Conseil. Explor. Mer, 3, 151. 